\title{
Measures of Industry Agglomeration in Brazil: a Study Addressing Neighboring Effects
}

\author{
Rafaella Stradiotto Vignandi* \\ José Luiz Parré** \\ Paulo Guimarães* *
}

\begin{abstract}
This paper addresses the impact of including neighboring effects to analyze the concentration status of some manufacturing sectors across the Brazilian mesoregions from 1995 through 2010. The analysis of spatially weighted indices - namely $H_{s}, G_{s}$ and $\gamma_{s}$ - points to a likely deconcentration process in most sectors of the Brazilian manufacturing industry in the period under study. In contrast to spatially unweighted indices, spatially weighted concentration indices proved to be more robust for addressing neighboring effects in the analysis of the (de)concentration process of the Brazilian industry.
\end{abstract}

Keywords: Manufacturing industry. Deconcentration. Neighboring effect. Space.

JEL Classification: R11; R12; R19.

\section{Introduction}

In general, industry is deemed as one of the major sectors providing for the socio-economic development of a country. It represents a strong link in the national production chain and stands out in comparison with other economic activities because of its potential to create jobs, produce revenues, attract investment, and pave the way to spillovers. One of the main characteristics of this dynamic sector is "change" - whether structural, economic, or geographical.

In the 1990s, an important modernization process boosted the Brazilian economy, having a significant effect on industry. This process included trade liberalization, market deregulation, and privatization of national companies. In addition, the stabilization of the Brazilian currency in 1994 had several macroeconomic effects. The successful control of inflation rates reduced the number of scenarios in the short term, improved the level of macroeconomic confidence, and allowed for management estimations to include larger time horizons. From a demand point of view, the redistributive effect on income following the fast drop of inflation rates

* $\quad$ MSc in Economics at State University of Maringá (UEM, Brazil). PhD student in Economics at Federal University of Minas Gerais (UFMG, Brazil). Scholarship from Capes. E-mail: rafaellasv@ gmail.com

** Doctor in Applied Economics from University of São Paulo (USP, Brazil). Professor, Department of Economics and Masters/Doctorate Program in Economics, State University of Maringá (UEM, Brazil). E-mail: jlparre@uem.br

** Ph.D. in Economics at University of South Carolina (USC, USA). Assistant Professor at the Darla Moore School of Business, University of South Carolina (USC, USA). E-mail: guimaraes@moore. sc.edu 
and the resumption of credit availability were key factors leading to consumption structuration and dynamism. These factors have contributed positively to increasing the rates of decisions to invest in fixed capital. In short, the structural plan implemented in 1994 was a milestone in the process of gaining macroeconomic stability in Brazil (KUPFER, 1998).

The literature on industry location points to factors that support and restrain industry concentration in a geographic area. Weber (1929) categorizes the factors influencing decisions of location as: a) Regional Factors: related to geographic distribution, such as transportation and workforce costs; or b) Local Factors: not influenced by geography. Local factors can be further categorized as either agglomerative or deglomerative. More recently, taking the so-called "New Economic Geography" approach, Krugman (1991) has referred to these factors respectively as centripetal forces (those that stimulate the concentration of economic activities), and centrifugal forces (those that are opposite to or restrain concentration, that is, those that lead to geographic deconcentration).

Most studies taking Krugman's (1991) approach and measures of spatial concentration to understand Brazilian industry have focused on aggregate analyses of the industry. Only recently have some studies been developed focusing on the analysis of concentration at cross-sectoral levels (cf., among others, SOUZA, 2002; RESENDE; WYLLIE, 2005; LAUTERT; ARAÚJO, 2007). To the best of our knowledge, however, the measures of concentration used in such studies have been limited to information within each areal unit, thus neglecting neighboring effects. For instance, the Herfindahl Index, an absolute measure of concentration, presupposes a homogeneous scenario, and does not compare a given variable with a reference distribution to gain understanding of its relative share. In other words, this index does not measure neighboring effect, and its results are eventually incomplete, as it does not account for permutations in spatial arrangements of the regions.

Against this background, this study aims at complementing unweighted indices with measures that capture the position of regions in space and account for neighboring effects. This allows for clustering regions and performing analyses that incorporate sets of industrial agglomerations and all possible inter-sectoral relationships of an industry that may trespass the boundaries of specific municipalities and micro-regions.

The spatial concentration tends to be measured based on the information about the exact location of each business unit. The use of techniques based in the spatial statistics for the analysis of spatial patterns pioneered the application of indicators related to spatial distance concentration..$^{1}$ In these studies, the authors relied on the existence of detailed micro-level data on employment and location for each

$1 \quad$ Read the papers of Marcon and Puech (2003), Duranton and Overman (2005) and Duranton and Overman (2008). 
plant. Most often, researchers only have access to the spatial aggregation of the data area and therefore resort to measurement of concentration indices that make use of this class of data. When applied to data area, the concentration measures are subject to known difficulties as "Modifiable Areal Unit Problem" (MAUP) and "checkerboard problem".

The MAUP refers to measurements based on data area with the highest sensitivity setting the limits used to build the unit area or how the space is clipped. Normally, one has to work with data in units of area and these are not necessarily significant to the problem in question, leading to a possible bias in the results.

Another limitation is found with the concentration measures related to "checkerboard problem". This "problem" refers to the fact that the measures ignore the geographical position of the regions, including the adjacent regions, although they are based on spatial data. Such statistics are shown only to the concentration with respect to units of area and ignore the effects neighbors. This means that the existing measures, based on area data are insensitive to the spatial position of the regions. Indeed, economic activity in a unit adjacent space is treated differently than the activity at the other end of a country (or region). The current space concentration of economic activity, however, does not recognize the area units. As a result of these spillovers, clusters of industries intersect area limits, and concentration measurements lose positions or order of regions in space.

According Arbia (2001) and Lafourcade and Mion (2007), point solutions are presented for this limitation that complement the information of spatial concentration measures such as the Gini coefficient Locational and/or the index of Ellison and Glaeser $(\hat{\gamma})$. For measures specifically designed to meet the spatial autocorrelation, we use the Moran's I statistic. ${ }^{2}$ More specifically, the goal of this paper is to understand how including neighboring effects in measures of spatial concentration has an impact on the statuses of sectors and meso-regions in the scope of the Brazilian manufacturing industry from 1995 through 2010.

This paper consists of five sections, including the Introduction and Final Remarks. Section 2 introduces a brief review of the major studies developed in Brazil with a focus on industry concentration. Section 3 describes the methodology used to approach both spatially unweighted and weighted concentration indices. Section 4 provides the data analysis.

$2 \quad$ The interest and concern about the influence of different space phenomena emerge officially in 1948 with the study of Moran, which introduces the first formal estimation of spatial dependence, the test $I$. By calculating the Moran's I can estimate the strength of spatial interaction to be performed, that is, a measure of correlation according to a certain criterion association variables. Can be formally expressed as follows: $I_{i}^{k l}=Z_{k \mathrm{i}} W Z_{l i}$ Where: $Z_{k \mathrm{i}}$ is the standardized variable; $W Z_{l i}$ is the spatial lag of the standardized variable. 


\section{Inter-Sectoral Industry Concentration and Applications to the Brazilian Context}

This section presents the major papers published in Brazil that approach industry concentration in the country and uses the Ellison-Glaeser index to analyze isolated periods of time. A few studies were found in the literature that analyzed this concentration index over a longer period of time, i.e., years.

Biderman (2004) mapped the concentration process onto a dynamic model in which companies decide their localization simultaneously. In an analysis of concentration according to industry qualification, one result that stood out was that low skilled sectors are originally clustered, whereas highly skilled sectors (i.e., technology-intensive sectors that demand a skilled workforce) are originally scattered. Over time, however, the levels of concentration reduced in both sectors. Particularly, deconcentration took place at a faster pace among low skilled sectors - a phenomenon that could be correlated to their higher initial levels of concentration. The result for the most concentrated sectors was as expected, as in principle losses of economies of scale tend to increase with concentration. The result for the originally deconcentrated sectors was also as expected, i.e., the levels of concentration did not vary over the decade (1991-2001).

According to the author, concentration may have relied on both spillovers and natural advantages. Low skilled sectors may also depend on natural resources at some level. This was true, for instance, for personal service sectors -- a subgroup of the low skilled sectors. However, concentration was lower for personal services than for the low skilled sectors altogether, while heterogeneity effects were stronger for the personal service sectors. In other words, overall deconcentration was greater among the low skilled sectors. Reduced concentration of low skilled sectors was consistent with reduced transportation costs. This may point to reduced advantages from agglomeration, and, therefore, reduced incentives to concentration.

Biderman (2004) also reports that the heterogeneity effect was reasonably weaker among highly skilled sectors. The reason is that such sectors must be closer to a skilled workforce, which, at least in principle, was not affected by reduced transportation costs. However, the low level of concentration of the highly skilled sectors is not perfectly consistent with the theory. As Biderman (2004) states, highly skilled sectors would most likely be in those places where the qualified workforce is concentrated.

A study developed by Resende and Wyllie (2005) assessed the industrial agglomeration of the manufacturing industry in Brazil in 1995 and 2001. It used the measures developed by Ellison and Glaeser (1997) with support by micro data compiled with a sound theoretical foundation. The study found evidence of substantial heterogeneity across several sectors. Among the leading industries were 
several technology sectors - a result partially consistent with those found in other countries, such as France and the United Kingdom. In addition, direct, substantial changes were observed in the industrial agglomeration patterns from 1995 to 2001 , implying skewness coefficients. In other words, the proportion of sectors at low levels of agglomeration increased from 1995 to 2001.

Lautert and Araújo (2007) analyzed the geographic concentration of the Brazilian manufacturing industry at the sectoral level in 1996 and 2001. The authors used the Ellison-Glaeser index (1997), a measure of concentration relatively unexplored in the literature on industry localization in Brazil. They detected a tendency toward geographic deconcentration, given the reduced mean index of industry concentration and the occurrence of deconcentration in most industrial sectors and groups under scrutiny. The authors also found some level of stability between the most concentrated and the least concentrated sectors, regardless of the occurrence of mobility within groups. In general, technology sectors, especially the producers of semi-finished and capital goods, were the most concentrated, while traditional industry groups, generally producers of non-durable consumer goods, were the least concentrated.

According to Lautert and Araújo (2007), no clear pattern was identified that could be generalized to the entire manufacturing industry. Most sectors of the Brazilian manufacturing industry had deagglomerative tendencies in the years studied, a period when the economic environment stimulated companies to adopt adjustment strategies. The authors' main findings are consistent with those reported by other scholars interested in the sectoral concentration of the manufacturing industry in 1996 and 2001, except for the greater mobility across the most concentrated sectors reported by Resende and Willie (2005).

Other research on the topic is reported by Camargo (2006), who studied the restructuration process of the Brazilian auto industry in the context of the changes that took place in the industry at the national level. The analysis focused on changes in competition patterns and market structures, and aimed at correlating such changes with the locational dynamics of this industrial segment. The author assessed the geographic distribution of the auto industry in Brazil, building on the joint analysis of market concentration and spatial concentration as measured using the Ellison-Glaeser (1997) indices of 1996 and 2001.

Camargo (2006) used the process of spatial deconcentration of the Brazilian manufacturing industry as a reference to the study of geographic concentration changes in the auto industry (as measured using the Ellison-Glaeser index). The variation found in the study pointed to a deeper process of geographic deconcentration in the auto industry activities when compared to that found for the manufacturing industry as a whole. The reduction of the index indicated a moderately lessened relevance of locational factors influencing the concentration of the Bra- 
zilian auto industry for the period. The index increased in 2000 and 2001. This increase was indicative of a change in the reduction of spatial deconcentration in the auto industry, especially considering that the manufacturing industry continued in that process.

\section{Methodology}

\subsection{Indices of Industry Agglomeration}

Like the Gini index, the Herfindahl index of industry concentration informs how much a given segment is unequally distributed in relation to the general employment or product concentration in a series of reference locations (HERFINDAHL, 1950). It is defined as:

$$
H=\sum_{i=1}^{n} s_{i}^{2} \quad \text { Equation } 1
$$

Rewriting Equation 1 gives:

$$
H=\sum_{i=1}^{n} s_{i} w_{i} \quad \text { Equation } 1.1
$$

In this procedure, the market share of each firm is transformed into the weights $w_{i}$, that is, $w_{i}=s_{i}$. By squaring each share $s_{i}$, a greater weight is assigned to the relatively larger shares.

The upper limit of this index is 1 , and represents a monopoly, as in this case $s_{i}=i$ for a given $i$ value, and $s_{j}=0$ for any $j \neq i$.

As the number of firms increases, the lower limit of the Herfindahl index decreases. When the number of firms tends to infinite, the minimum value of the index clearly tends to zero (HERFINDAHL, 1950).

The concentration measures proposed by Ellison and Glaeser (1997) and Maurel and Sedillot (1999) can be considered as more general indices aimed at controlling size difference across multiple industrial sectors in relation to the industry as a whole (RESENDE; WYLLIE, 2005).

These measures also apply to assessing industrial activity concentration, and for this purpose they are referred to as Gini Index or Hoover Index (HOOVER, 1936). This adaptation to produce the Hoover Index includes information regarding the share of employment (or product) that the regions have within an industrial sector in comparison to overall employment in the industry.

Ellison and Glaeser (1997, p. 895) considered a group of industries $j=1$, $2, \ldots, n$, and supposed that a geographic whole is divided into subareas $I$, and that $S_{i j}, S_{2 j}, \ldots, S_{i j}$ are the industry's or sector's shares $j$ contained in each of these areas. 
Letting $x_{1}, x_{2}, \ldots, x_{i}$ be some other measure of the size of these areas (e.g., each area's share of population or aggregate employment), the authors concluded that a simple measure of the raw geographic concentration of industry $j$ is:

$$
G=\sum_{i=1}^{I}\left(s_{i j}-x_{i}\right)^{2} \quad \text { Equation } 2
$$

where $s_{i}$ is location i's share of overall sectoral employment in the manufacturing industry (i.e., in relation to the sector), and $x_{i}$ indicates locations $i$ 's share of overall employment in the whole manufacturing industry.

Applying this indicator has some advantages, such as: easy interpretation, immediate comparison between activity sectors, and it is relative to the local economic scale, instead of simply pinpointing a location's share of sectoral employment or production. Nevertheless, it also features some pitfalls, such as: it sensitive both to the geographic units selected as reference (spatial divisions) and to the level of sectoral aggregation adopted.

Ellison, Glaeser and Kerr (2007) were aware of the problems arising from applying such measures to cross-region or cross-country analyses. The results would be invariably sensitive to both the size distribution of plants in the industry and the fitness of the available geographic data. The authors, therefore, proposed an alternative measure of agglomeration, herein referred to as $\hat{\gamma}$ :

$$
\gamma=\frac{\widehat{G}-\left(1-\sum_{i} x_{i}^{2}\right) H}{\left(1-\sum_{i} x_{i}^{2}\right)(1-H)} \quad \text { Equation } 3
$$

where:

- $\widehat{G} \equiv G=\sum_{i}\left(S_{i j}-x_{i}\right)^{2}$ represents an estimator of "natural" (absolute) concentration;

- $\left(1-\sum_{i} X_{i}^{2}\right)$ stands for the regional distribution of overall employment (if it equals 1 , the distribution is equitable); and

- $H=\sum_{j} s_{i j}{ }^{2}$ is the Herfindahl index of industry concentration (the nearer $H$ is to 1 , the larger the industry concentration ).

In conclusion, the authors favor an index of geographic concentration combining $G$ and the Herfindahl index to address the impact of locational factors on the geographic concentration of industry. The higher the index, the larger the impact of location factors on the geographic concentration of the manufacturing industry. By the same token, the lower the index, the lower the impact of these factors on the geographic concentration of industry.

In relating a measure of spatial concentration with a measure of market structure concentration, the Ellison-Glaeser index makes up for the effect of internal economies of scale (the Herfindahl index includes in the $\hat{\gamma}$ index the distribution of the plants according to their sizes). The result is the net effect of location factors upon the geographic concentration of industrial activities. Consequently, the $\hat{\gamma}$ 
index allows for analytically relating market structure with concentration, as it includes both technical scale and spatial localization. In addition, it allows for comparing the level of geographic concentration across industries in reference to the spatial distribution of the manufacturing industry. The aim is to identify potential excesses of geographic concentration (ELLISON; GLAESER; KERR, 2007, p. 7).

\subsection{Spatial Agglomeration and Neighboring Effects}

According to Guimarães, Figueiredo and Woodward (2011), a number of straightforward changes can be applied to the Herfindahl index to address the neighboring effects more effectively. This revisited statistics can be conceived of as a quadratic form associated to the identity matrix (Id). Admitting the spatial interactions between all terms, Equation 1 can be formally rewritten as follows:

$$
H_{s}=s^{\prime} \Psi s \quad \text { Equation } 4
$$

where: $\Psi$ is a matrix of spatial weights with generic, non-null elements $\Psi_{i j}$ on the main diagonal. The matrix $\Psi$ is designed to account for spillovers that trespass the boundaries of the area under scrutiny. It can be rendered in several different ways, but this study approaches it as $\Psi=I d+W$, where $W$ is the conventional, row-standardized contiguity matrix with zeros on the diagonal. If no neighboring effects apply, then $\Psi=I d$, giving the traditional Herfindahl Index the spatially weighted version of the Herfindahl index is bounded - if all regions have neighbors - in the $[1 / J, 1]^{3}$ interval.

The definition of a spatial weight matrix $(\mathrm{W})$ is based on the continuity, which, in turn, may be defined as a neighborhood, and the geographic distance and the social-economic combination of both. The analysis of many results in spatial econometrics depends on the choice of the spatial weights matrix, ie, a discussion regarding the types of matrices is a very important and crucial in the spatial econometric literature. The binary matrix of spatial weights can be prepared in accordance with the idea of continuity, the definition of which is that two regions are neighbors if they share a common physical boundary. According to this concept of continuity is given a unit value in the array to two neighboring regions, otherwise it is assigned a null value.

$3 \quad$ Please note that $\left(\sum s_{j}\right)^{2}=H+2 \sum \sum_{i \neq j} s_{i} s_{j}=1$ and $H_{s}=s^{\prime}(I d+W) s=H+s^{\prime} W s$. Because the upper limit of the off-diagonal elements of $W$ is 1 , it follows that $H_{s}$ will never be greater than 1 . In contrast, $H$ reaches its lowest bound of $1 / J$ when the $s_{j}$ 's are equal for all regions. In addition, $s$ is a positive definite quadratic form, which implies that $H_{s}$ will never be lower than $1 / J$. 
Formally we have:

$$
\begin{aligned}
& W_{i j}=1 \text { if } i \text { and } j \text { are continuous } \\
& \\
& 0 \text { if } i \text { and } j \text { are not continuous }
\end{aligned}
$$

By convention, $W_{i j}=0$ represents that no neighboring region i can be herself. This happens because, once calculating the trace of the matrix of spatial weights, and the trace is represented as the sum of the diagonal elements of the matrix, whether these are zero, the trace will be a null value also facilitating a series accounts.

Despite the apparent simplicity of the concept, there have been several possibilities to define the neighborhood, according to different conventions continuity. The problem is configured as specified in the definition of the geographical border through the observation of a map. The map, despite being a good representation of the actual geographic configuration also contains measurement errors. Considering these measurement errors and in reference to the movement of pieces on a chessboard, the matrix used to implement the convention Brazilian was like "Queen" (considering the matrix endogenously in the proceedings). For this definition, which is adopted across borders with non-zero length, can be considered the vertices (nodes) in the map view as continuous. This matrix was chosen because it showed the highest and best values of Moran's I, as recommended by Almeida (2004). The weight matrix for the Brazilian case was constructed from the 137 meso-regions and across the 23 sectors that make up the manufacturing industry in Brazil, considering the classification of the CNAE. However, it is important to note that other mothers were tested, such as the Rook, Bishop and K-neighbors.

It follows that the spatially weighted Herfindahl index combines the information from both the traditional Herfindahl index and Moran's I statistics:

$$
H_{s}=H+s^{\prime} \text { Ws Equation 4.1, }
$$

where $s^{\prime} W s=M\left(H-J^{-1}\right)+J^{-1} i^{\prime} W s$

Considering the relation between Moran's I statistics and the spatially weighted version of the Herfindahl index:

$$
H_{s}=M\left(H-J^{-1}\right)+H+k_{1} \quad \text { Equation 4.2, }
$$

where: $\mathrm{k}_{1}=J^{-1} \mathrm{i}^{\prime} \mathrm{W}$ is a spatially weighted mean of the shares. $H_{s}$ is an increasing function of $H$ (a measure of spatial concentration within regions) and $M$ (a measure of spatial concentration across regions that captures the neighboring effects). 
Guimarães, Figueiredo and Woodward (2011) state that this idea can be applied to the raw concentration index, referred to as the Ellison-Glaeser Index. In this case, a spatially weighted version could be rendered as:

$$
G_{s}=(s-x)^{\prime} \Psi(s-x) \quad \text { Equation } 5
$$

The relation between $G_{s}$ and Moran's I can be defined as follows:

$$
\begin{array}{lr}
G_{s}=G+(s-x)^{\prime} W(s-x) & \text { Equation 5.1, } \\
G_{s}=G+M_{D} G & \text { Equation 5.2, }
\end{array}
$$

where the index $M_{D}$ is added to indicate that Moran's I is applied to different regions.

Using $G_{s}$ as a starting point, Guimarães, Figueiredo and Woodward (2011) also pointed to the possibility of applying the same procedure used for the Ellison-Glaeser Index (1997) to derive a spatially weighted version of EG $(\hat{\gamma})$ index. Thus, using the weighted version of the Ellison-Glaeser index gives:

$$
\widehat{\gamma_{S}}=\frac{G_{S}-H_{I}\left(1-x^{\prime} \Psi x\right)}{\left(1-H_{I}\right)\left(1-x^{\prime} \Psi x\right)} \quad \text { Equation } 6
$$

For $\Psi=I d$, the index gives way to the standard EG. With the neighboring effect, $\widehat{\gamma}_{S}$ is a reparameterization of index $G_{s}$ and, as such, will monotonically behave with the $G_{s}$ for a spatial structure $(\Psi)$ and reference distribution $(x)$. This means that $\widehat{\gamma_{s}}$ is also monotonically related to $M_{D}$ (Moran's I applied to differences in the shares). Thus, it is possible to demonstrate that:

$$
\hat{\gamma}_{s}^{*}=\hat{\gamma}_{*}\left(1+M_{D}\right) k_{2} \quad \text { Equation } 6.1
$$

where: $\mathrm{k}_{2}$ is a constant equal to $\frac{1-x{ }^{\prime} x}{1-x^{\prime} \Psi x}$, and $\hat{\gamma}_{s}^{*}$ and $\hat{\gamma}_{*}$ are rescaled versions of $\widehat{\gamma_{s}}$ and $\hat{\gamma}$.

In essence, Guimarães, Figueiredo, Woodward (2011) proposes applying an "inflation factor" of $\left(1+M_{D}\right) k_{2}$ to the common EG index $(\hat{\gamma})$ to account for the level of spatial autocorrelation across regions. This "inflation factor" will be equal to 1 under the null hypothesis of no spatial autocorrelation, $E\left(M_{D}\right)$, and, thus, $\widehat{\gamma_{S}}$ e $\hat{\gamma}$ will produce exactly the same results. In addition, if $M_{D}>E\left(M_{D}\right)$, then $\widehat{\gamma_{S}}$ will be larger than $\hat{\gamma}$, and the reverse is true if $M_{D}<E\left(M_{D}\right)$. 


\subsection{Variable Description and Secondary Data}

The variable used in this study to calculate both the standard and the spatially changed indexes of Herfindahl, Raw Geographic Concentration, and Ellison-Glaeser was: number of firms as identified in a secondary database comprising data from the Annual Report of Social Information developed by the Brazilian Ministry of Labor and Employment (RAIS/MTE). The data comprises the years 1995, 2000, 2005 , and 2010. All concentration indexes mentioned in sections 4.1 and 4.2 were calculated using scripts specifically developed for the statistical software package Stata.

The set of data involves the results of the equations introduced in the previous section, which were spatially measured considering the 137 Brazilian meso-regions and the 23 sectors that made up the manufacturing industry from 1995 to 2010. These data served as input to the standard and modified analyses of spatial concentration and, therefore, to the observation of the potential changes in the status of sectors and regions in relation to the overall industry in Brazil in the period under scrutiny.

A new code of economic activities was implemented in 1995 (CNAE/IBGE), producing data that are inconsistent for analysis with data from the previous years, especially in the case of more fine-grained data. The Ministry of Labor and Employment (1999) has sought to map new data onto the old codification, but the data are assumed to be reliable only down to the level of the 26 subsectors of the economy (NAJBERG; OLIVEIRA, 1999).

Given the use of secondary data on the number of firms as published in the Annual Report of Social Information, the analyses included an assessment of the effect of this method on the results. For the sake of consistency, the analysis focused on the data related to the CNAE 95, which basically corresponds to the CNAE 1.0. This was assumed to make up for the changes in sector classification in Brazil (CNAE 1.01 and CNAE 2.0) and ensure the feasibility of computing the spatial concentration indexes using the variable of choice over the selected period.

\section{Results and Discussion}

\subsection{Industry Agglomeration in Brazil from 1995 to 2010: an Unweighted Analysis}

This section reports on the results after computing the Herfindahl $(\mathrm{H})$, Raw Concentration (G), and Ellison-Glaeser ( $\gamma$ ) Indexes as spatially unweighted measures, following Equations 1, 2, and 3 respectively. Tables 1 and 2 show the results of the three indexes in relation to the manufacturing industry sectors in 1995, 2000, 2005, and 2010.

VIGNANDI, R. S.; PARRÉ, J. L.; GUIMARÃES, P. Measures of Industry Agglomeration... 
In some sectors shown in Table 1, geographic concentration decreased in the 1995/2000 period. Considering the most clustered sectors - Sectors 16 (Manufacturing of Tobacco Products), 19 (Manufacturing of Leather and Leather Products), 23 (Manufacturing of Coke, Nuclear Fuel, Ethanol, and Oil Refinery), 32 (Manufacturing of Electronic Material, and Communication Equipment and Devices), and 35 (Manufacturing of Other Transportation Equipment) --, the only ones that experienced increased concentration were Sectors 16 and 23. The other three sectors faced substantial reductions according to the three industry concentration indexes for 1995 and 2000.

Table 1 - Unweighted Herfindahl, Raw Concentration, and Ellison-Glaeser Indexes ofthe Brazilian Manufacturing Industry in years 1995 and 2000

\begin{tabular}{|c|c|c|c|c|c|c|}
\hline \multirow[t]{2}{*}{1995} & \multirow[b]{2}{*}{$\mathbf{H}$} & \multirow[b]{2}{*}{ G } & \multirow[b]{2}{*}{$\gamma$} & \multicolumn{2}{|l|}{2000} & \multirow[b]{2}{*}{$\gamma$} \\
\hline & & & & $\mathbf{H}$ & G & \\
\hline Sector 15 & 0.02933 & 0.029668 & 0.03217 & 0.02407 & 0.01986 & 0.02099 \\
\hline Sector 16 & 0.12069 & 0.106027 & 0.11494 & 0.16374 & 0.14586 & 0.15414 \\
\hline Sector 17 & 0.07619 & 0.014313 & 0.01552 & 0.06353 & 0.01963 & 0.02075 \\
\hline Sector 18 & 0.09672 & 0.010725 & 0.01163 & 0.0585 & 0.01265 & 0.01337 \\
\hline Sector 19 & 0.17393 & 0.166655 & 0.1807 & 0.14743 & 0.13568 & 0.14343 \\
\hline Sector 20 & 0.03079 & 0.061898 & 0.06712 & 0.03239 & 0.0536 & 0.05666 \\
\hline Sector 21 & 0.10808 & 0.008827 & 0.00957 & 0.07639 & 0.00779 & 0.00823 \\
\hline Sector 22 & 0.17281 & 0.027589 & 0.02991 & 0.14888 & 0.03402 & 0.03596 \\
\hline Sector 23 & 0.04129 & 0.074802 & 0.0811 & 0.04162 & 0.07571 & 0.08120 \\
\hline Sector 24 & 0.19058 & 0.033199 & 0.036 & 0.14439 & 0.0306 & 0.03234 \\
\hline Sector 25 & 0.19007 & 0.030214 & 0.03276 & 0.13149 & 0.02173 & 0.02297 \\
\hline Sector 26 & 0.04439 & 0.015354 & 0.01665 & 0.0308 & 0.01327 & 0.01402 \\
\hline Sector 27 & 0.10427 & 0.019806 & 0.02147 & 0.08064 & 0.02199 & 0.02324 \\
\hline Sector 28 & 0.15034 & 0.015828 & 0.01716 & 0.10644 & 0.01249 & 0.0132 \\
\hline Sector 29 & 0.13881 & 0.015026 & 0.01629 & 0.10284 & 0.01351 & 0.01428 \\
\hline Sector 30 & 0.26593 & 0.076449 & 0.08286 & 0.16449 & 0.05032 & 0.05315 \\
\hline Sector 31 & 0.19846 & 0.036652 & 0.03974 & 0.15389 & 0.0342 & 0.03615 \\
\hline Sector 32 & 0.21049 & 0.090169 & 0.09777 & 0.14231 & 0.06925 & 0.07319 \\
\hline Sector 33 & 0.16863 & 0.025391 & 0.02751 & 0.13308 & 0.02646 & 0.02795 \\
\hline Sector 34 & 0.26719 & 0.074259 & 0.08053 & 0.16962 & 0.04628 & 0.04893 \\
\hline Sector 35 & 0.17976 & 0.104570 & 0.11338 & 0.13542 & 0.0879 & 0.0929 \\
\hline Sector 36 & 0.06924 & 0.009673 & 0.01049 & 0.05082 & 0.00742 & 0.00784 \\
\hline
\end{tabular}




\begin{tabular}{cccc|ccc}
\hline 1995 & & & & $\mathbf{2 0 0 0}$ & & \\
& H & G & $\gamma$ & H & G & $\gamma$ \\
\hline Sector 37 & 0.06491 & 0.020998 & 0.02258 & 0.04615 & 0.00972 & 0.01017 \\
\hline
\end{tabular}

Source: Authors' table building on the RAIS/MTE database (BRASIL, 2010).

Individual analysis of the Ellison-Glaeser indexes shows that Manufacturing of Leather and Leather Products was the sector that experienced the greatest reduction in concentration (0.0373), dropping from 0.1807 in 1995 to 0.1434 in 2000. The index for Sector 32 (Electronic Materials and Communication Equipment and Devices) dropped from 0.0977 in 1995 to 0.0731 in 2000, i.e., a reduction of 0.0246 in the Ellison-Glaeser index. In Sector 32, the greatest drop in the period was registered by the Herfindahl sub-index: 0.0682. In Sector 35 (Manufacturing of Other Transportation Equipment), the reduction was of 0.0204 (from 0.1133 to 0.0929), the Herfindahl index being the sub-index that experienced the greatest drop (thus contributing to the decrease in the Ellison-Glaeser index) - a drop of 0.0443.

Manufacturing of Tobacco Products was one of the sectors that underwent increased concentration: from 0.1149 in 1995 to 0.1541 in 2000, an increase of 0.0392 . The sub-index with major contribution to this increase was the Herfindahl index, with an increment of 0.0430. Manufacturing of Coke, Nuclear Fuel, Ethanol, and Oil Refinery experienced a mild variation, and the indexes remained stable in this period.

In Table 2, geographic concentration decreased in some sectors in the period from 2005 to 2010 as well. Considering the five most concentrated sectors - Sectors 16 (Manufacturing of Tobacco Products), 19 (Manufacturing of Leather and Leather Products), 23 (Manufacturing of Coke, Nuclear Fuel, Ethanol, and Oil Refinery), 32 (Manufacturing of Electronic Material and Communication Equipment and Devices), and 35 (Manufacturing of Other Transportation Equipment) -, Sector 23 was the only ones that experienced increased concentration. The other four sectors experienced substantial deconcentration according to the three indexes of industry concentration related to the $2005 / 2010$ period.

Table 2 - Unweighted Herfindahl, Raw Concentration, and Ellison-Glaeser Indexes of the Brazilian Manufacturing Industry in years 2005 and 2010

\begin{tabular}{llcl|ccc}
\hline \multicolumn{1}{c}{2005} & & & & $\mathbf{2 0 1 0}$ & \\
& $\mathbf{H}$ & $\mathbf{G}$ & \multicolumn{1}{c|}{$\gamma$} & $\mathbf{H}$ & $\mathbf{G}$ & $\gamma$ \\
\hline Sector 15 & 0.02254 & 0.01932 & 0.020201 & 0.02093 & 0.01787 & 0.01861 \\
Sector 16 & $\mathbf{0 . 1 4 8 7 6}$ & $\mathbf{0 . 1 1 4 3 7}$ & $\mathbf{0 . 1 1 9 5 6 0}$ & $\mathbf{0 . 1 3 7 7}$ & $\mathbf{0 . 1 1 1 9 9}$ & $\mathbf{0 . 1 1 6 5 9}$ \\
Sector 17 & 0.06239 & 0.02228 & 0.023298 & 0.06181 & 0.02374 & 0.02472 \\
\hline
\end{tabular}




\begin{tabular}{|c|c|c|c|c|c|c|}
\hline \multirow[t]{2}{*}{2005} & \multirow[b]{2}{*}{$\mathbf{H}$} & \multirow[b]{2}{*}{$\mathbf{G}$} & \multirow[b]{2}{*}{$\gamma$} & \multicolumn{2}{|l|}{2010} & \multirow[b]{2}{*}{$\gamma$} \\
\hline & & & & $\mathbf{H}$ & $\mathbf{G}$ & \\
\hline Sector 18 & 0.04964 & 0.01233 & 0.012890 & 0.04781 & 0.01301 & 0.01355 \\
\hline Sector 19 & 0.10863 & 0.09966 & 0.104222 & 0.09056 & 0.08614 & 0.08972 \\
\hline Sector 20 & 0.03067 & 0.04331 & 0.045287 & 0.02845 & 0.03345 & 0.03484 \\
\hline Sector 21 & 0.0662 & 0.00746 & 0.007797 & 0.06505 & 0.00802 & 0.00834 \\
\hline Sector 22 & 0.11726 & 0.02711 & 0.028343 & 0.11535 & 0.02985 & 0.03109 \\
\hline Sector 23 & 0.04549 & 0.0603 & 0.063053 & 0.18474 & 0.15263 & 0.15895 \\
\hline Sector 24 & 0.12353 & 0.02933 & 0.030674 & 0.07904 & 0.01367 & 0.01424 \\
\hline Sector 25 & 0.11008 & 0.02061 & 0.021554 & 0.09212 & 0.01571 & 0.01636 \\
\hline Sector 26 & 0.02755 & 0.01148 & 0.012000 & 0.02442 & 0.00854 & 0.00889 \\
\hline Sector 27 & 0.07505 & 0.02146 & 0.022435 & 0.06802 & 0.02068 & 0.02154 \\
\hline Sector 28 & 0.08688 & 0.01117 & 0.011680 & 0.0717 & 0.00797 & 0.00829 \\
\hline Sector 29 & 0.08528 & 0.01231 & 0.012866 & 0.06397 & 0.00736 & 0.00767 \\
\hline Sector 30 & 0.11277 & 0.03941 & 0.041188 & 0.11716 & 0.07103 & 0.07396 \\
\hline Sector 31 & 0.11045 & 0.0231 & 0.024158 & 0.09367 & 0.01881 & 0.01959 \\
\hline Sector 32 & 0.19436 & 0.14095 & 0.147398 & 0.15822 & 0.09866 & 0.10274 \\
\hline Sector 33 & 0.12845 & 0.03083 & 0.032220 & 0.09874 & 0.0189 & 0.01967 \\
\hline Sector 34 & 0.1414 & 0.04104 & 0.042917 & 0.11878 & 0.03286 & 0.03422 \\
\hline Sector 35 & 0.12146 & 0.09173 & 0.095918 & 0.09982 & 0.07863 & 0.08189 \\
\hline Sector 36 & 0.04426 & 0.00764 & 0.007991 & 0.04041 & 0.00843 & 0.00878 \\
\hline Sector 37 & 0.03604 & 0.00698 & 0.007256 & 0.04168 & 0.01055 & 0.01096 \\
\hline
\end{tabular}

Source: Authors' table building on the RAIS/MTE database (BRASIL, 2010).

Individual analysis of the Ellison-Glaeser index indicated that Manufacturing of Tobacco Products experienced a very mild concentration variation and remained virtually stable in the period. Manufacturing of Leather and Leather Products suffered the greatest index reduction (0.0373), going from 0.1042 in 2005 to 0.0897 in 2010, the Herfindahl index being the sub-index with the greatest drop: 0.0181. The Electronic Materials and Communication Equipment and Devices index dropped from 0.1473 in 2005 to 0.1027 in 2010, i.e., a drop of 0.0446 , the greatest decrease in the 2005 and 2010 periods. The Manufacturing of Other Transportation Equipment index decreased from 0.0959 in 2005 to 0.018 in 2010, i.e., a drop of 0.0141 . The sub-index that accounted for the greatest drop (thus contributing to the decrease in the Ellison-Glaeser index) was the Herfindahl index - a drop of 0.0216 . 
Manufacturing of Coke, Nuclear Fuel, Ethanol, and Oil Refinery was one of the few sectors that experienced increased concentration: from 0.063 in 2005 to 0.1589 in 2010, i.e., an increment of 0.0959 . The sub-index that contributed most to this increase was the Herfindahl index, with an increment of 0.0430 .

These results seem to be partially consistent with those reported in Biderman (2004), who analyzed a dynamic model in which companies decided their location simultaneously. The author first claimed that the low skilled sectors were originally concentrated, while the highly skilled industries were originally more deconcentrated. The author also claimed that the level of concentration decreased in both sectors, but it took place at a faster pace among the less qualified sectors. The results herein described, however, do not support the claim that the low skilled industries are originally clustered, while the more qualified sectors are originally declustered. On the other hand, the second claim seems to be consistent with the present analyses of the tables containing the concentration indexes of the Brazilian industry over the period under scrutiny.

Table 3 provides the Ellison-Glaeser indexes of concentration in the sectors as established by CNAE. The table contains the absolute values of the indexes as well as the ranking of the 23 sectors for an easier analysis of geographic concentration changes that took place in 1995, 2000, 2005, and 2010. As the table shows, concentration increased in six sectors $\left(17,18,22,23,27\right.$, and 32) ${ }^{4}$ while they decreased in the other 17 sectors $(15,16,19,20,21,24,25,26,28,29,30,31,33,34$, 35,36 , and $37^{5}$ ). However, variations were very small in some sectors (e.g., 18, 21 , 27, and 30).

$4 \quad$ Respectively, Manufacturing of Textile Products; Clothes and Accessories; Press and Audio-visual Reproductions; Coke, Nuclear Fuel, Ethanol, and Oil Refinery; Basic Metallurgy; and Manufacturing of Electronic Materials and Communication Equipment and Devices.

5 Respectively, Manufacturing of Food and Beverage; Tobacco Products, Leather and Leather Products; Travel Products and Shoes; Wood Products; Cellulose, Paper, and Paper Products; Chemicals; Rubber and Plastic Products; Non-Metallic Mineral Products; Metal Products, Except for Machinery and Equipment; Machinery and Equipment; Office Machines and Computer Equipment; Electrical Machines, Devices and Materials; Medical-Hospital Equipment; Precision and Optical Instruments; Industrial Automation Equipment, Chronometers and Watches; Vehicles, Trailers, and Truck Bodies; Other Transportation Equipment; Furniture and Miscellaneous Industrial Products; and Recycling. 
Table 3 - Unweighted Ellison-Glaeser Indexes and Ranking of the

BrazilianManufacturing Sectors in 1995, 2000, 2005, and 2010

\begin{tabular}{|c|c|c|c|c|c|c|c|c|}
\hline & \multicolumn{2}{|l|}{1995} & \multicolumn{2}{|l|}{2000} & \multicolumn{2}{|l|}{2005} & \multicolumn{2}{|l|}{2010} \\
\hline & $\gamma$ & Rank & $\gamma$ & Rank & $\gamma$ & Rank & $\gamma$ & Rank \\
\hline Division 15 & 0.032173 & 12 & 0.02099 & 15 & 0.020201 & 16 & 0.01860641 & 14 \\
\hline Division 16 & 0.11494 & 2 & 0.154139 & 1 & 0.119560 & 2 & 0.116587 & 2 \\
\hline Division 17 & 0.015518 & 20 & 0.020745 & 16 & 0.023298 & 13 & 0.024724 & 10 \\
\hline Division 18 & 0.011627 & 21 & 0.0133735 & 19 & 0.012890 & 17 & 0.013546 & 17 \\
\hline Division 19 & 0.1807027 & 1 & 0.143429 & 2 & 0.104222 & 3 & 0.089716 & 4 \\
\hline Division 20 & 0.0671187 & 8 & 0.0566649 & 6 & 0.045287 & 6 & 0.0348383 & 7 \\
\hline Division 21 & 0.0095654 & 23 & 0.008228 & 22 & 0.007797 & 22 & 0.00834 & 21 \\
\hline Division 22 & 0.0299139 & 13 & 0.035955 & 10 & 0.028343 & 11 & 0.031089 & 9 \\
\hline Division 23 & 0.0811007 & 6 & 0.080018 & 4 & 0.063053 & 5 & 0.158945 & 1 \\
\hline Division 24 & 0.035998 & 10 & 0.0323422 & 11 & 0.030674 & 10 & 0.014236 & 16 \\
\hline Division 25 & 0.032761 & 11 & 0.022966 & 14 & 0.021554 & 15 & 0.016362 & 15 \\
\hline Division 26 & 0.016646 & 18 & 0.014019 & 18 & 0.012000 & 19 & 0.008893 & 19 \\
\hline Division 27 & 0.021474 & 16 & 0.023237 & 13 & 0.022435 & 14 & 0.02153809 & 11 \\
\hline Division 28 & 0.017161 & 17 & 0.013196 & 20 & 0.011680 & 20 & 0.00829426 & 22 \\
\hline Division 29 & 0.016291 & 19 & 0.014279 & 17 & 0.012866 & 18 & 0.0076668 & 23 \\
\hline Division 30 & 0.0828566 & 5 & 0.053145 & 7 & 0.041188 & 8 & 0.0739586 & 6 \\
\hline Division 31 & 0.0397404 & 9 & 0.036148 & 9 & 0.024158 & 12 & 0.0195912 & 13 \\
\hline Division 32 & 0.097768 & 4 & 0.0731912 & 5 & 0.147398 & 1 & 0.1027402 & 3 \\
\hline Division 33 & 0.02751 & 14 & 0.027948 & 12 & 0.032220 & 9 & 0.01966632 & 12 \\
\hline Division 34 & 0.080525 & 7 & 0.0489258 & 8 & 0.042917 & 7 & 0.034218 & 8 \\
\hline Division 35 & 0.1133755 & 3 & 0.092896 & 3 & 0.095918 & 4 & 0.081889 & 5 \\
\hline Division 36 & 0.0104851 & 22 & 0.0078398 & 23 & 0.007991 & 21 & 0.008775 & 20 \\
\hline Division 37 & 0.0225807 & 15 & 0.0101678 & 21 & 0.007256 & 23 & 0.0109573 & 18 \\
\hline
\end{tabular}

Source: Authors' table building on the RAIS/MTE database (BRASIL, 2010).

An analysis of the relative changes revealed that one sector held the same ranking (Sector 16) over the years, 12 lost their ranking (Sector 15, 19, 24, 25, $26,28-30,31,34,35$, and 37), and 10 became relatively more concentrated (Sectors $17,18,20-23,27,32,33$, and 36). Changes, though, were slight in some sectors. These findings indicate a trend towards industry deconcentration in the years studied.

These findings corroborate the results reported by Resende and Wyllie (2005) and Lautert and Araújo (2007). These authors showed that the most concentrated sectors comprise both activities that use natural materials as input (e.g., those related to Leather and Shoes) and activities that involve more technology and investments (e.g., those related to Coke, Nuclear Fuel, Ethanol, and Oil). Some sectors are characterized as located near the agricultural sources of raw materials (e.g., Manufacturing of Tobacco Products) and/or experiencing the influence of economies of agglomeration, as is the case of spillovers provided by other industries that carry out activities somewhat related to these sectors. In addition, some sectors can be deemed as more sensitive to economies of agglomeration, such as Manufacturing of Electronic Materials and Communication Equipment and Devices, and Manufacturing of Other Transportation Equipment. The least concentrated sectors were usually those involving traditional industrial activities, such as Manu- 
facturing of Furniture and Miscellaneous Industrial Products, Recycling, Manufacturing of Cellulose, Paper and Paper Products, and Manufacturing of Machinery and Equipment.

Overall, ranking changed significantly over the years studied, with sectors gaining or losing several places from one period to another. Among the most concentrated sectors, those in the first to fifth places in the ranking, the results stood out in the case of Sectors 23 (Manufacturing of Coke, Nuclear Fuels, Ethanol, and Oil Refinery) and 32 (Manufacturing of Electronic Material and Communication Equipment and Devices), which respectively advanced their places from 6th to 1 st and from 4th to 3rd when compared to their concentration in 1995 and 2010. Sector 16 (Manufacturing of Tobacco Products) remained stable in second place in 1995, 2005, and 2010. Sectors 19 (Manufacturing of Leather and Leather Products) and 35 (Manufacturing of Other Transportation Equipment) dropped in their ranking, which is somewhat indicative of industry deconcentration. Sector 19 fell from 1st place in 1995 to 4th place in 2010, and Sector 35 fell from 3rd to 5th place in the same period.

This finding is consistent with that reported by Camargo (2006), who studied the restructuration process of the Brazilian auto industry in the context of the changes that took place in the industry at the national level. The author also pointed out that the process of geographic deconcentration was deeper in the auto industry than in the manufacturing industry as a whole.

\subsection{Industry Agglomeration in Brazil from 1995 to 2010: a Weighted Analysis}

This section reports the findings after computing the Herfindahl $(\mathrm{H})$, Raw Concentration (G), and Ellison-Glaeser ( $\gamma$ ) Indexes as spatially unweighted measures, following Equations 4, 5, and 6 respectively. Tables 4 and 5 show the results of the weighted Ellison-Glaeser indexes of some sectors of the manufacturing industry in 1995, 2000, 2005, and 2010. They also display the overall Moran's I for all sectors that made up the Brazilian manufacturing industry in that period. Moran's I statistics breaks down the overall index of autocorrelation to the level of the individual local contribution. Two different types of spatial weight matrices were tested to support the spatially weighted analyses, namely the Queen type and the Rook Type. The Queen type matrix provided the most meaningful results, which led to it being chosen for data analysis.

As shown in Table 4, geographic concentration retrenched in some sectors of the manufacturing industry from 1995 to 2000 . The sectors chosen for a more fine-grained analysis were not necessarily the least and the most concentrated ones according to the absolute values of the spatially weighted indexes of Herfindahl $\left(\mathrm{H}_{\mathrm{s}}\right)$ 
, Raw Concentration $\left(G_{s}\right)$ and Ellison-Glaser $\left(\gamma_{s}\right)$, but rather those that yielded consistent results in all measures, especially regarding both global and local Moran's Is.

Considering the sectors that stood out in the analyses - namely Sectors 19 (Manufacturing of Leather and Leather Goods), 20 (Manufacturing of Wood Products) 23 (Manufacturing of Coke, Nuclear Fuel, Ethanol, and Oil Refinery), 29 (Manufacturing of Machinery and Equipment) 32 (Manufacturing of Electronic Material and Communication Equipment and Devices), 34 (Manufacturing and Assembly of Vehicles, Trailers and Truck Bodies), and 35 (Manufacturing of Other Transportation Equipment) --, the only one that experienced increased concentration was Sector 23. However, this increase was insignificant. On the other hand, reductions in the industry concentration indexes were meaningful in the following sectors during the 1995-2000 periods: Manufacturing of Leather and Leather Products, Manufacturing of Machinery and Equipment, Manufacturing of Electronic Material and Communication Equipment and Devices, Manufacturing and Assembly of Vehicles, Trailers and Truck Bodies, and Manufacturing of Other Transportation Equipment.

Table 4 - Unweighted Herfindahl, Raw Concentration, and Ellison-Glaeser Indexes ofthe Brazilian Manufacturing Industry in years 2005 and 2010

\begin{tabular}{ccccc|cccc}
\hline 1995 & & & & & $\mathbf{2 0 0 0}$ & & & \\
& Hs & Gs & $I$ Moran & $\gamma_{s}$ & Hs & Gs & $I$ Moran & $\gamma_{s}$ \\
\hline Sector 15 & 0.041 & 0.033 & 0.117 & 0.036 & 0.034 & 0.023 & 0.150 & 0.024 \\
Sector 16 & 0.124 & 0.102 & -0.035 & 0.113 & 0.173 & 0.144 & -0.010 & 0.155 \\
Sector 17 & 0.091 & 0.014 & 0.012 & 0.016 & 0.078 & 0.021 & 0.061 & 0.022 \\
Sector 18 & 0.106 & 0.011 & 0.058 & 0.012 & 0.067 & 0.013 & 0.067 & 0.014 \\
Sector 19 & $\mathbf{0 . 1 9 9}$ & $\mathbf{0 . 1 8 1}$ & $\mathbf{0 . 0 8 4}$ & $\mathbf{0 . 1 9 9}$ & $\mathbf{0 . 1 6 8}$ & $\mathbf{0 . 1 4 9}$ & $\mathbf{0 . 0 9 8}$ & $\mathbf{0 . 1 6 0}$ \\
Sector 20 & $\mathbf{0 . 0 4 9}$ & $\mathbf{0 . 0 7 3}$ & $\mathbf{0 . 1 8 1}$ & $\mathbf{0 . 0 8 0}$ & $\mathbf{0 . 0 5 1}$ & $\mathbf{0 . 0 6 6}$ & $\mathbf{0 . 2 3 8}$ & $\mathbf{0 . 0 7 1}$ \\
Sector 21 & 0.124 & 0.009 & 0.044 & 0.010 & 0.093 & 0.008 & 0.082 & 0.009 \\
Sector 22 & 0.179 & 0.024 & -0.044 & 0.029 & 0.155 & 0.032 & -0.048 & 0.035 \\
Sector 23 & $\mathbf{0 . 0 5 4}$ & $\mathbf{0 . 0 8 6}$ & $\mathbf{0 . 1 5 3}$ & $\mathbf{0 . 0 9 5}$ & $\mathbf{0 . 0 5 6}$ & $\mathbf{0 . 0 8 9}$ & $\mathbf{0 . 1 7 9}$ & $\mathbf{0 . 0 9 6}$ \\
Sector 24 & 0.208 & 0.035 & 0.059 & 0.039 & 0.161 & 0.032 & 0.056 & 0.035 \\
Sector 25 & 0.206 & 0.031 & 0.015 & 0.034 & 0.149 & 0.023 & 0.053 & 0.025 \\
Sector 26 & 0.058 & 0.015 & -0.007 & 0.017 & 0.043 & 0.013 & 0.005 & 0.014 \\
Sector 27 & 0.124 & 0.023 & 0.174 & 0.026 & 0.100 & 0.026 & 0.164 & 0.027 \\
Sector 28 & 0.171 & 0.017 & 0.091 & 0.019 & 0.124 & 0.013 & 0.065 & 0.014 \\
Sector 29 & $\mathbf{0 . 1 5 8}$ & $\mathbf{0 . 0 1 7}$ & $\mathbf{0 . 1 0 8}$ & $\mathbf{0 . 0 1 8}$ & $\mathbf{0 . 1 2 4}$ & $\mathbf{0 . 0 1 6}$ & $\mathbf{0 . 1 6 2}$ & $\mathbf{0 . 0 1 7}$ \\
Sector 30 & 0.274 & 0.075 & -0.025 & 0.082 & 0.190 & 0.057 & 0.129 & 0.061 \\
Sector 31 & 0.218 & 0.038 & 0.027 & 0.041 & 0.175 & 0.036 & 0.060 & 0.039 \\
Sector 32 & $\mathbf{0 . 2 4 1}$ & $\mathbf{0 . 0 9 8}$ & $\mathbf{0 . 0 8 2}$ & $\mathbf{0 . 1 0 7}$ & $\mathbf{0 . 1 7 3}$ & $\mathbf{0 . 0 7 5}$ & $\mathbf{0 . 0 8 0}$ & $\mathbf{0 . 0 8 0}$ \\
Sector 33 & 0.178 & 0.024 & -0.041 & 0.027 & 0.144 & 0.026 & -0.028 & 0.028 \\
Sector 34 & $\mathbf{0 . 3 0 8}$ & $\mathbf{0 . 0 8 6}$ & $\mathbf{0 . 1 6 0}$ & $\mathbf{0 . 0 9 5}$ & $\mathbf{0 . 2 0 5}$ & $\mathbf{0 . 0 5 5}$ & $\mathbf{0 . 1 9 3}$ & $\mathbf{0 . 0 5 9}$ \\
Sector 35 & $\mathbf{0 . 1 9 7}$ & $\mathbf{0 . 1 0 2}$ & $\mathbf{- 0 . 0 2 3}$ & $\mathbf{0 . 1 1 2}$ & $\mathbf{0 . 1 6 9}$ & $\mathbf{0 . 0 8 5}$ & $\mathbf{- 0 . 0 3 6}$ & $\mathbf{0 . 0 9 1}$ \\
Sector 36 & 0.081 & 0.010 & 0.032 & 0.011 & 0.063 & 0.007 & -0.002 & 0.008 \\
Sector 37 & 0.078 & 0.023 & 0.097 & 0.025 & 0.059 & 0.010 & 0.032 & 0.011 \\
\hline
\end{tabular}

Source: Authors' table building on the RAIS/MTE database (BRASIL, 2010).

According to an individual analysis of the Ellison-Glaeser indexes, Manufacturing of Leather and Leather Goods was the sector that saw the greatest drop 
(0.039), i.e., from 0.199 in 1995 to 0.16 in 2000. The Manufacturing of Wood Products index dropped from 0.08 in 1995 to 0.071 in 2000, the Hernfindahl Index being the sub-index that most contributed to this decline (0.009). The Manufacturing of Machinery and Equipment index dropped from 0.018 in 1995 to 0.017 in 2000, the Hernfindahl index being the sub-index with the greatest decrease (0.034). The Manufacturing of Electronic Materials and Communication Equipment and Devices index dropped from 0.107 in 1995 to 0.08 in 2000, i.e., a reduction of 0.0246. In this sector, the greatest drop was registered by the Herfindahl index: 0.068. The Manufacturing and Assembly of Vehicles, Trailers and Truck Bodies index fell from 0.095 in 1995 to 0.059 in 2000, and once again, the Herfindahl index was the sub-index that registered the greatest concentration loss (0.103). The Manufacturing of Other Transportation Equipment index decreased from 0.112 in 1995 to 0.091 in 2000 , i.e., a drop of 0.021 . The sub-index that accounted for the greatest drop (thus contributing to the decrease in the Ellison-Glaeser index) was, again, the Herfindahl index - a drop of 0.028 .

As shown in Table 5, geographic concentration retrenched in some sectors from 2005 to 2010 as well. Considering the sectors that stood out in the overall findings, that is, Sectors 19 (Manufacturing of Leather and Leather Goods), 20 (Manufacturing of Wood Products) 23 (Manufacturing of Coke, Nuclear Fuel, Ethanol, and Oil Refinery), 29 (Manufacturing of Machinery and Equipment) 32 (Manufacturing of Electronic Material and Communication Equipment and Devices), 34 (Manufacturing and Assembly of Vehicles, Trailers and Truck Bodies), and 35 (Manufacturing of Other Transportation Equipment), Sector 23 was the only one that experienced significantly increased concentration. In contrast, reduced concentration indexes were meaningful in the following sectors: Manufacturing of Leather and Leather Products, Manufacturing of Wood Products, Manufacturing of Machinery and Equipment, Manufacturing of Electronic Material and Communication Equipment and Devices, Manufacturing and Assembly of Vehicles, Trailers and Truck Bodies, and Manufacturing of Other Transportation Equipment. 
Table 5 - Weighted Herfindahl, Raw Concentration, and Ellison-Glaeser Indexes of the Brazilian Manufacturing Industry in years 2005 and 2010

\begin{tabular}{|c|c|c|c|c|c|c|c|c|}
\hline \multirow[t]{2}{*}{2005} & \multirow[b]{2}{*}{ Hs } & \multirow[b]{2}{*}{ Gs } & \multirow[b]{2}{*}{ I Moran } & \multirow[b]{2}{*}{$\gamma_{s}$} & \multicolumn{2}{|l|}{2010} & \multirow[b]{2}{*}{ I Moran } & \multirow[b]{2}{*}{$\gamma_{s}$} \\
\hline & & & & & Hs & Gs & & \\
\hline Sector 15 & 0.033 & 0.023 & 0.178 & 0.024 & 0.031 & 0.021 & 0.185 & 0.022 \\
\hline Sector 16 & 0.158 & 0.114 & -0.007 & 0.120 & 0.153 & 0.117 & 0.045 & 0.123 \\
\hline Sector 17 & 0.077 & 0.023 & 0.052 & 0.025 & 0.077 & 0.025 & 0.064 & 0.027 \\
\hline Sector 18 & 0.059 & 0.013 & 0.054 & 0.014 & 0.056 & 0.014 & 0.065 & 0.015 \\
\hline Sector 19 & 0.126 & 0.110 & 0.099 & 0.116 & 0.103 & 0.093 & 0.081 & 0.098 \\
\hline Sector 20 & 0.050 & 0.055 & 0.264 & 0.058 & 0.046 & 0.043 & 0.283 & 0.045 \\
\hline Sector 21 & 0.082 & 0.008 & 0.111 & 0.009 & 0.082 & 0.009 & 0.138 & 0.010 \\
\hline Sector 22 & 0.124 & 0.026 & -0.052 & 0.027 & 0.122 & 0.028 & -0.046 & 0.030 \\
\hline Sector 23 & 0.056 & 0.071 & 0.176 & 0.075 & 0.192 & 0.156 & 0.025 & 0.165 \\
\hline Sector 24 & 0.139 & 0.031 & 0.053 & 0.033 & 0.092 & 0.015 & 0.072 & 0.015 \\
\hline Sector 25 & 0.128 & 0.022 & 0.078 & 0.024 & 0.111 & 0.018 & 0.123 & 0.019 \\
\hline Sector 26 & 0.039 & 0.012 & 0.011 & 0.012 & 0.035 & 0.009 & 0.062 & 0.010 \\
\hline Sector 27 & 0.094 & 0.025 & 0.165 & 0.026 & 0.086 & 0.024 & 0.137 & 0.025 \\
\hline Sector 28 & 0.106 & 0.013 & 0.146 & 0.014 & 0.088 & 0.009 & 0.101 & 0.009 \\
\hline Sector 29 & 0.106 & 0.015 & 0.184 & 0.015 & 0.083 & 0.009 & 0.212 & 0.009 \\
\hline Sector 30 & 0.146 & 0.048 & 0.210 & 0.050 & 0.152 & 0.071 & 0.005 & 0.075 \\
\hline Sector 31 & 0.131 & 0.025 & 0.091 & 0.027 & 0.115 & 0.022 & 0.148 & 0.023 \\
\hline Sector 32 & 0.207 & 0.143 & 0.012 & 0.151 & 0.173 & 0.100 & 0.015 & 0.106 \\
\hline Sector 33 & 0.145 & 0.032 & 0.052 & 0.034 & 0.115 & 0.020 & 0.058 & 0.021 \\
\hline Sector 34 & 0.173 & 0.049 & 0.186 & 0.052 & 0.148 & 0.039 & 0.183 & 0.041 \\
\hline Sector 35 & 0.154 & 0.099 & 0.079 & 0.105 & 0.123 & 0.083 & 0.058 & 0.088 \\
\hline Sector 36 & 0.056 & 0.008 & 0.005 & 0.008 & 0.051 & 0.009 & 0.046 & 0.009 \\
\hline Sector 37 & 0.046 & 0.007 & 0.045 & 0.008 & 0.051 & 0.011 & 0.032 & 0.011 \\
\hline
\end{tabular}

Source: Authors' table building on the RAIS/MTE database (BRASIL, 2010).

Individual analysis of the Ellison-Glaeser indexes shows that the Manufacturing of Leather and Leather Goods sector saw the greatest drop (0.018), i.e., from 0.116 in 2005 to 0.0098 in 2010 . The Manufacturing of Wood Products index dropped from 0.058 in 2005 to 0.045 in 2010, the Herfindahl index being the sub-index that most contributed to deconcentration (0.013). The Manufacturing of Machinery and Equipment index fell from 0.015 in 2005 to 0.009 in 2010, the Herfindahl index being the sub-index with greatest decrease (0.023). The Manufacturing of Electronic Materials and Communication Equipment and Devices index dropped from 0.151 in 2005 to 0.106 in 2010 , i.e., a drop of 0.045 ; in this sector, the greatest drop was registered by the Herfindahl index: 0.034. The Manufacturing and Assembly of Vehicles, Trailers and Truck Bodies index fell from 0.052 in 2005 to 0.041 in 2010, and once again, the Herfindahl index was the sub-index that registered the greatest concentration loss (0.025). The Manufacturing of Other Transportation Equipment index decreased from 0.105 in 2005 to 0.088 in 2010, i.e., a drop of 
0.017; in this case, the sub-index that accounted for the greatest drop (thus contributing to the decrease in the Ellison-Glaeser index) was the Herfindahl index - a drop of 0.031 .

Manufacturing of Coke, Nuclear Fuel, Ethanol, and Oil Refinery was one of the few sectors that experienced increased concentration: from 0.075 in 2005 to 0.165 in 2010, a concentration increase of 0.09 . The sub-index that contributed most to this increase was the Herfindahl index, with an increment of 0.136.

Table 6 presents the Ellison-Glaeser indexes of concentration in the industrial sectors as defined by CNAE. In addition to the indexes' absolute values, the table also includes the ranking of the 23 industrial sectors for an easier analysis of the geographic concentration changes that took place in 1995, 2000, 2005, and 2010.

According to the table, concentration increased in 9 sectors (17, 28, 20, 21$23,27,31$, and 32), ${ }^{6}$ while it decreased in 11 sectors $(15,19,24-26,28-30,34,35$, and 37). ${ }^{7}$ Some variations were very slight, implying stability over the years studied (cf. Sectors 16, 33, and $36^{8}$ ). These findings seem to indicate a trend towards industry deconcentration in the selected sectors over the period under scrutiny.

6 Respectively: Manufacturing of Textile Products; Clothes and Accessories; Wood Products; Cellulose, Paper, and Paper Products; Press and Audiovisual Reproduction; Coke, Nuclear Fuel, Ethanol, and Oil Refinery; Basic Metallurgy; Electrical Machines, Devices and Materials; and Electronic Material and Communication Equipment and Devices.

7 Respectively: Manufacturing of Food and Beverage; Leather and Leather Products; Travel Products and Shoes; Chemicals; Rubber and Plastic Products; Non-Metallic Products; Metal Products, Except for Machines and Equipment; Machines and Equipment; Office Machine and Computer Equipment; Vehicle, Trailers, and Truck Bodies; Other Transportation Equipment; and Recycling.

These sectors are made up of: Manufacturing of Tobacco Products; Medical and Hospital Equipment; Precision and Optical Instruments; Industrial Automation Equipment, Chronometers, and Watches; and Furniture and Miscellaneous Industrial Products. 
Table 6 - Weighted Ellison-Glaeser Indexes and Ranking of the Brazilian Manufacturing Industry in 1995, 2000, 2005, and 2010

\begin{tabular}{ccccccccc}
\hline & $\mathbf{1 9 9 5}$ & & $\mathbf{2 0 0 0}$ & & $\mathbf{2 0 0 5}$ & & $\mathbf{2 0 1 0}$ & \\
& $\gamma_{s}$ & Rank & $\gamma_{s}$ & Rank & $\gamma_{s}$ & Rank & $\gamma_{s}$ & Rank \\
\hline Sector 15 & 0.036450 & 11 & 0.024471 & 15 & 0.024105 & 15 & 0.022331 & 13 \\
Sector 16 & 0.112580 & 2 & 0.15465 & 2 & 0.1202403 & 2 & 0.123405 & 2 \\
Sector 17 & 0.015940 & 20 & 0.02231 & 16 & 0.024825 & 14 & 0.02664 & 10 \\
Sector 18 & 0.012470 & 21 & 0.014461 & 18 & 0.013758 & 18 & 0.0146056 & 17 \\
Sector 19 & $\mathbf{0 . 1 9 8 7 9 0}$ & $\mathbf{1}$ & $\mathbf{0 . 1 5 9 5 8}$ & $\mathbf{1}$ & $\mathbf{0 . 1 1 6 0 0 0 4}$ & $\mathbf{3}$ & $\mathbf{0 . 0 9 8 2 3}$ & $\mathbf{4}$ \\
Sector 20 & $\mathbf{0 . 0 8 0 4 3 0}$ & $\mathbf{8}$ & $\mathbf{0 . 0 7 1 1 1 1}$ & $\mathbf{6}$ & $\mathbf{0 . 0 5 7 9 9 1}$ & $\mathbf{6}$ & $\mathbf{0 . 0 4 5 2 5 2}$ & 7 \\
Sector 21 & 0.010130 & 23 & 0.009025 & 22 & 0.0087762 & 21 & 0.009621 & 19 \\
Sector 22 & 0.029010 & 13 & 0.03468 & 10 & 0.0272281 & 11 & 0.030035 & 9 \\
Sector 23 & $\mathbf{0 . 0 9 4 8 8 0}$ & $\mathbf{5}$ & $\mathbf{0 . 0 9 5 5 9}$ & $\mathbf{3}$ & $\mathbf{0 . 0 7 5 0 9 9}$ & $\mathbf{5}$ & $\mathbf{0 . 1 6 4 9 1}$ & $\mathbf{1}$ \\
Sector 24 & 0.038680 & 10 & 0.03462 & 11 & 0.032717 & 10 & 0.0154534 & 16 \\
Sector 25 & 0.033750 & 12 & 0.024522 & 14 & 0.023533 & 16 & 0.018604 & 15 \\
Sector 26 & 0.016775 & 19 & 0.01428 & 19 & 0.0122933 & 20 & 0.009568 & 20 \\
Sector 27 & 0.025584 & 15 & 0.02741 & 13 & 0.0264827 & 13 & 0.024794 & 11 \\
Sector 28 & 0.018997 & 17 & 0.014251 & 20 & 0.0135574 & 19 & 0.0092483 & 23 \\
Sector 29 & $\mathbf{0 . 0 1 8 3 1 9}$ & $\mathbf{1 8}$ & $\mathbf{0 . 0 1 6 8 2}$ & $\mathbf{1 7}$ & $\mathbf{0 . 0 1 5 4 2 6}$ & $\mathbf{1 7}$ & $\mathbf{0 . 0 0 9 4 1 1}$ & $\mathbf{2 1}$ \\
Sector 30 & 0.082010 & 7 & 0.06081 & 7 & 0.050498 & 8 & 0.075291 & 6 \\
Sector 31 & 0.041390 & 9 & 0.03882 & 9 & 0.026699 & 12 & 0.022777 & 12 \\
Sector 32 & $\mathbf{0 . 1 0 7 3 5 0}$ & $\mathbf{4}$ & $\mathbf{0 . 0 8 0 4 5 3}$ & $\mathbf{5}$ & $\mathbf{0 . 1 5 1 0 5 4}$ & $\mathbf{1}$ & $\mathbf{0 . 1 0 5 6 6}$ & $\mathbf{3}$ \\
Sector 33 & 0.026770 & 14 & 0.027552 & 12 & 0.0343247 & 9 & 0.021078 & 14 \\
Sector 34 & $\mathbf{0 . 0 9 4 7 6 6}$ & $\mathbf{6}$ & $\mathbf{0 . 0 5 9 1 4}$ & $\mathbf{8}$ & $\mathbf{0 . 0 5 1 5 4 9}$ & 7 & $\mathbf{0 . 0 4 1 0 1}$ & $\mathbf{8}$ \\
Sector 35 & $\mathbf{0 . 1 1 2 4 5 1}$ & $\mathbf{3}$ & $\mathbf{0 . 0 9 0 7 7}$ & $\mathbf{4}$ & $\mathbf{0 . 1 0 4 8 0 5}$ & $\mathbf{4}$ & $\mathbf{0 . 0 8 7 7 2 2}$ & $\mathbf{5}$ \\
Sector 36 & 0.010978 & 22 & 0.007928 & 23 & 0.0081322 & 22 & 0.009291 & 22 \\
Sector 37 & 0.025166 & 16 & 0.0106449 & 21 & 0.0076847 & 23 & 0.0114479 & 18 \\
\hline
\end{tabular}

Source: Authors' table building on the RAIS/MTE database (BRASIL, 2010).

Individual analysis of the Ellison-Glaeser indexes shows that the Manufacturing of Leather and Leather Goods sector saw the greatest drop (0.018), i.e., from 0.116 in 2005 to 0.0098 in 2010 . The Manufacturing of Wood Products index dropped from 0.058 in 2005 to 0.045 in 2010, the Herfindahl index being the sub-index that most contributed to deconcentration (0.013). The Manufacturing of Machinery and Equipment index fell from 0.015 in 2005 to 0.009 in 2010, the Herfindahl index being the sub-index with greatest decrease (0.023). The Manufacturing of Electronic Materials and Communication Equipment and Devices index dropped from 0.151 in 2005 to 0.106 in 2010, i.e., a drop of 0.045; in this sector, the greatest drop was registered by the Herfindahl index: 0.034. The Manufacturing and Assembly of Vehicles, Trailers and Truck Bodies index fell from 0.052 in 2005 to 0.041 in 2010, and once again, the Herfindahl index was the sub-index that registered the greatest concentration loss (0.025). The Manufacturing of Other Transportation Equipment index decreased from 0.105 in 2005 to 0.088 in 2010, i.e., a drop of 
0.017; in this case, the sub-index that accounted for the greatest drop (thus contributing to the decrease in the Ellison-Glaeser index) was the Herfindahl index - a drop of 0.031 .

Manufacturing of Coke, Nuclear Fuel, Ethanol, and Oil Refinery was one of the few sectors that experienced increased concentration: from 0.075 in 2005 to 0.165 in 2010, a concentration increase of 0.09 . The sub-index that contributed most to this increase was the Herfindahl index, with an increment of 0.136.

Table 6 presents the Ellison-Glaeser indexes of concentration in the industrial sectors as defined by CNAE. In addition to the indexes' absolute values, the table also includes the ranking of the 23 industrial sectors for an easier analysis of the geographic concentration changes that took place in 1995, 2000, 2005, and 2010.

According to the table, concentration increased in 9 sectors $(17,28,20,21$ 23, 27, 31, and 32), ${ }^{9}$ while it decreased in 11 sectors (15, 19, 24-26, 28-30, 34, 35, and 37). ${ }^{10}$ Some variations were very slight, implying stability over the years studied (cf. Sectors 16, 33, and $36^{11}$ ). These findings seem to indicate a trend towards industry deconcentration in the selected sectors over the period under scrutiny.

In general, some sectors stood out more intensely than others by their relative importance in a given meso-region analysis. These sectors are more sensitive to the presence of industries "neighbors" to influence the dynamics of the production process and tend to gain a more highlights in the analysis. Besides the comparative advantage that exists in some divisions of the Brazilian manufacturing industry in the period studied, such as: related sectors Manufacturing of Textile Products; Clothes and Accessories; Wood Products; Cellulose, Paper, and Paper Products; Coke, Nuclear Fuel, Ethanol, and Oil Refinery; Basic Metallurgy; Electrical Machines, Devices and Materials; and Electronic Material and Communication Equipment and Devices. These economic activities assisted with greater force agglomerative these segments of Brazilian industry mentioned above.

The study of Guimarães, Figueiredo and Woodward (2011) make the application of this new methodology developed by them to the case of the North American industry, in order to demonstrate that the proposed new tools and methods are well may be useful for regional analysis. The authors illustrate the case of the Tobacco industry, who consider certain degree of concentration in the southeas-

9 Respectively: Manufacturing of Textile Products; Clothes and Accessories; Wood Products; Cellulose, Paper, and Paper Products; Press and Audiovisual Reproduction; Coke, Nuclear Fuel, Ethanol, and Oil Refinery; Basic Metallurgy; Electrical Machines, Devices and Materials; and Electronic Material and Communication Equipment and Devices.

10 Respectively: Manufacturing of Food and Beverage; Leather and Leather Products; Travel Products and Shoes; Chemicals; Rubber and Plastic Products; Non-Metallic Products; Metal Products, Except for Machines and Equipment; Machines and Equipment; Office Machine and Computer Equipment; Vehicle, Trailers, and Truck Bodies; Other Transportation Equipment; and Recycling.

11 These sectors are made up of: Manufacturing of Tobacco Products; Medical and Hospital Equipment; Precision and Optical Instruments; Industrial Automation Equipment, Chronometers, and Watches; and Furniture and Miscellaneous Industrial Products. 
tern region of the United States while for Railroad Rolling Stock industry for several concentration points around the country. For comparison analysis between the non- weighted indicators and spatially weighted authors reported no significant difference as "ranking" of segments and more concentrated to the less concentrated. As for the Brazilian case it was observed that this difference is more visible than that presented by the North American results. This point is that you can try and ascertain the importance of measuring this article for the Brazilian scenario.

\section{Final Remarks}

This paper aimed at understanding how including the neighboring effect in measures of spatial concentration has an impact on the statuses of sectors and meso-regions in the scope of the Brazilian industry from 1995 through 2010. To accomplish the aim, it first introduced the spatially unweighted indexes of Herfindahl, Raw Geographic Concentration, and Ellison-Glaeser to subsequently contrast them with their respective spatially modified versions. The ultimate objective was to identify concentration status variations derived from comparing the results of standard spatial concentration measures with the results of indexes that account for neighboring effects.

In particular, this study presented an alternative approach to the standard measurement of (de)concentration in the Brazilian industry. This alternative methodology prevents the so-called "checkerboard problem" and "modifiable areal unit problem MAUP", concerned with the sensitivity of the measures to areal data. This paper suggests an alternative and differentiated approach, as - to the best of our knowledge - no other study in the Brazilian literature account for neighboring effects that may impact on their results regarding industry concentration. Therefore, this study is insightful and pioneering in this type of analysis and paves the way for future research to include the spatial weight matrix (neighboring effects) in the indexes of industry concentration in Brazil.

Data analysis particularly focused on assessing the efficacy of applying the spatially weighted method to study industry concentration in Brazil. The results of the model's application were further analyzed with a view to assessing its relevance to the analysis of the reality and spatial interpretation in Brazil. In assessing the relevance of the measures, the findings indicated that spatially weighted measures were more robust for the analysis than the spatially unweighted method.

The results point out that the spatially weighted indexes of concentration more clearly show the possible deconcentration process of most sectors that make up the manufacturing industry in Brazil from 1995 to 2010. More specifically, the spatially calculated indexes clearly indicated a deconcentration process in most of the sectors herein investigated, especially Manufacturing of Leather and Leather 
Products (Sector 19), Manufacturing of Machinery and Equipment (Sector 29), Manufacturing and Assembly of Vehicles, Trailers and Truck Bodies (Sector 34), and Manufacturing of Other Transportation Equipment (Sector 35).

One of the few sectors that presented a considerable increase in the level of concentration was Sector 23 (Manufacturing of Coke, Nuclear Flue, Ethanol, and Oil Refinery). This may be related to the influence of the pre-salt oil and companies related to this Brazilian economic sector since 2006-2007. The production structure of this sector has undergone important changes in Brazil over the last 10 years. Part of these changes took place upon the approval of 9th Amendment to the Brazilian Constitution, which terminated, in 1995, the state monopoly of oil exploration in Brazil (until then under the control of PETROBRAS). The end of PETROBRAS' monopoly was an important milestone, yet it has not put an end to the concentration of these economic activities. Currently, PETROBRAS holds over 50 $\%$ of the production included in Sector 23.

When compared to the spatially unweighted indexes, the spatially weighted indexes shed light on and expose the interference of neighboring effects, as they account for the presence (or absence) of neighbors affecting the results. This is particularly true for the analysis of the (de)concentration process of Brazilian industry in recent years, i.e., after the stabilization of the Brazilian currency (1995-2010). Therefore, including neighboring effect in the analysis of spatial concentration indices seems to improve the robustness of the findings and produce results that are closer to reality.

Given the potential of taking such an alternative approach, this study can serve as input or a starting point for the development of future studies. Potential developments of this research include improving the method building on a "single" index that accounts for all of the sectors making up the manufacturing industry in Brazil and carrying out a spatially weighted analysis of industry concentration per Brazilian region.

\section{Appendix A - Additional Statistical Indices of Industrial Agglomeration Spa- tially Weighted}

In order to analyze some statistics from spatially weighted indexes to enhance the results and discussions held section 4.2 below presents a statistical supplement. The spatially weighted indices selected for this analysis were the latest over the period of years analyzed, ie, the indices for the year 2010 (Herfindahl $\left(H_{s}\right)$ Concentration-Press $\left(G_{s}\right)$ and Ellison-Glaeser $\left(\gamma_{s}\right)$ because it believes that these indicators are more current/recente, considering that this is one of the most important contribution of this study and also by limiting the number of pages of this paper.

VIGNANDI, R. S.; PARRÉ, J. L.; GUIMARÃES, P. Measures of Industry Agglomeration... 
A descriptive analysis of a statistical distribution is important because, in addition to determining a measure of central tendency, allows knowing the data dispersion and shape distribution. The analysis of the histograms, and measures skewness and kurtosis of a variable relating to the shape, the arrangement and the relative position of a given distribution, and a good indication of normality of data. According to Milone (2004) distribution is symmetric when said elements equidistant from the center have the same frequency, happening so its mean is equal to its median, and can be defined as the difference between mean and median, and between average and fashion. For kurtosis, defined as the flattening of the characteristic curve of the distribution, reflecting the difference between the curve in question, and usually flattened. Thus, we applied such features basic statistics, and obtained the following results:

Table 7 - Descriptive Statistics of spatially weighted índices

Herfindahl,Concentration-Press and Ellison-Glaeser for the year 2010

\begin{tabular}{ccccc}
\hline & Mean & Standard Deviation & Variance & Kurtosis \\
\hline$H_{s}$ & 0.0993478 & 0.0444048 & 0.0019718 & 2.290476 \\
$G_{s}$ & 0.041087 & 0.0414114 & 0.0017149 & 3.859607 \\
$\gamma_{s}$ & 0.0433043 & 0.0438079 & 0.0019191 & 3.861023 \\
\hline
\end{tabular}

Source: Prepared by using Stata 12.0.

As revealed in Table 7 and the histograms (Figure 1) can be verified that the Herfindahl spatially weighted $\left(H_{s}\right)$ for the year 2010 is the closest to a normal curve format. The highest values of this variable are often in the range of 0.10 , a range that characterizes a situation of industrial decentralization. This occurrence happens similarly in the other two indices spatially weighted Concentration-Press $\left(G_{s}\right)$ and Ellison and Glaeser $\left(\gamma_{s}\right)$. But the greatest frequency values are in the range of 0.05 , confirming a trend of industrial decentralization in the three indicators.

The skewness and kurtosis are important because of theoretical considerations concerning the statistical inference. The skewness measures the degree of deviation from the symmetry of a distribution. It is positive for asymmetric distributions to the right and negative for the asymmetric left. For symmetric distributions the value is zero (MILONE, 2004). For the calculated indices observed positive skewness, that is, there is a concentration values on the graph to lower values, as can be seen also in the analysis performed in Section 4.2, by examining Tables 4, 5 and 6 , respectively. 
Figure 1 - Histograms of distribution of spatially weighted indices, Herfindahl, Concentration-Press and Ellison and Glaeser, for the year 2010 with normal

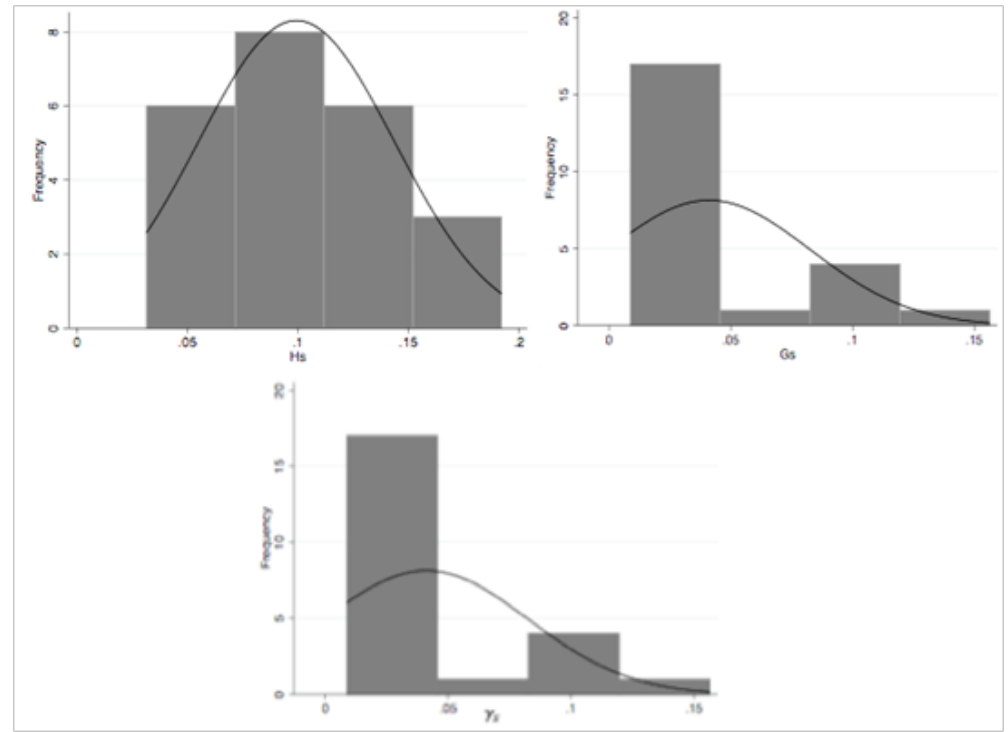

Source: Prepared by using Stata 12.0.

With respect to kurtosis in the curve of probability distribution function ascertained that the Herfindahl index $\left(H_{s}\right)$ showed a value less than 3 is called platykurtic distribution function. The other indices, namely: Concentration-Press $\left(G_{s}\right)$ and Ellison-Glaeser $\left(\gamma_{s}\right)$ showed values above 3 being characterized as leptokurtic distribution function. Therefore, this analysis follows using the non-parametric tests applied to spatially weighted indexes: Herfindahl $\left(\mathrm{H}_{s}\right)$ Concentration-Press $\left(G_{s}\right)$ and Ellison-Glaeser $\left(\gamma_{s}\right)$.

To analyze the dispersion of the 23 sectors that make up the Brazilian Manufacturing Industry in the year 2010 we will examine the correlation of spatially weighted indices presented in Figure 2. 
Figure 2 - Dispersion indices spatially weighted Herfindahl, Concentration-Press and Ellison and Glaeser, for the year 2010 regarding the 23 sectors that make up the Brazilian Manufacturing Industry

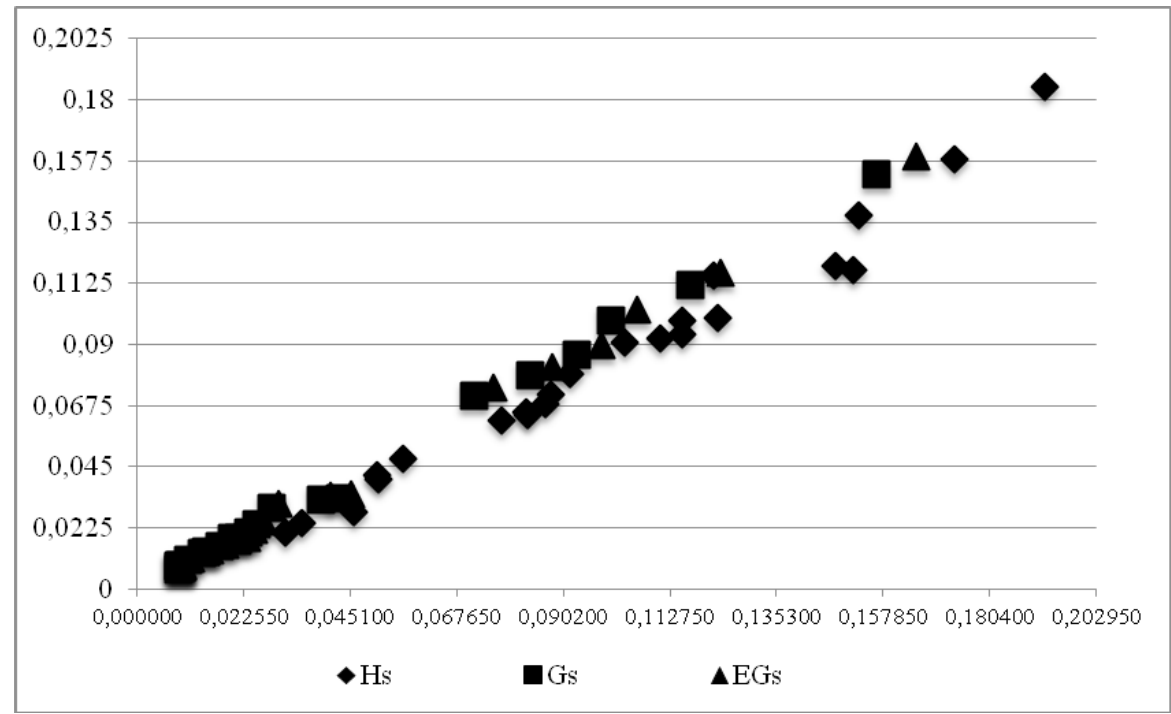

Source: Prepared by using Stata 12.0.

The prediction for the spatially weighted Herfindahl index $\left(H_{s}\right)$ as for the other two indices spatially weighted Concentration-Press $\left(G_{s}\right)$ and Ellison and Glaeser $\left(\gamma_{s}\right)$ is what is happening a possible devolution of Brazilian Manufacturing Industry. As can be seen by means of Figure 2, for the Herfindahl index ( $H_{s}$, blue dots), most industries are concentrated in the range of 0.05 to 0.15 . To indexes Concentration-Press $\left(G_{s}\right)$ and Ellison and Glaeser $\left(\gamma_{s}\right)$, which are respectively represented by red and green dots, the concentration of most Brazilian industrial sectors happen in the range 0 to 0.05 .

Despite this scenario possible industrial decentralization through the Graph 2 we can see that there is a correlation between the spatially weighted indices for the year 2010. This is what is possible to explain the variations that occur in spatially weighted indices from changes occurring in these indexes industrial (de)concentration in Brazil. This result is completely relevant to everything discussed so far and can be reaffirmed by making a study of the equations of this paper presented in section 3.2.

To complete this complementary statistical analysis of the indices of industrial concentration spatially weighted $\left(H_{s}, G_{s}\right.$ and $\left.\gamma_{s}\right)$ examine the correlation matrix of Spearman ( $\rho$ : rho), based on a "rank correlacion", and significance $(p)$ of this coefficient correlation between indices. The linear correlation coefficient involve va- 
riables that measure the degree of association or mutual linear relationship between the variables selected for the correlation test (BUNCHAFT, KELLNER, 1999).

The coefficient is dimensionless and lies in the range $-1 \leq \rho \leq 1$. The closer these extremes, the greater the association between variables. The negative sign means that the correlation variables vary in the opposite direction, that is, higher categories of a variable are associated with lower categories of another variable (SIEGEL, 1975). The statistical validity of the linear correlation coefficient assumes that the variables are random and comes from a "population" bivariate normal. This coefficient is not sensitive to asymmetries in the distribution, or the presence of outliers (GUILFORD, 1950).

As already discussed above and in Figures 1 and Dispersion (Figure 2) can be verified by means of Spearman matrix (Table 8 ) the strong correlation between the spatially weighted indices, considering the 23 sectors that comprise the Manufacturing Industry in Brazil in 2010. All indices showed an positive correlation is higher than 0.66 , intensified by a statistically significant in all cases with $\mathrm{p}$ values between 0.0000 to 0.0005 (extremely low).

Table 8 - Correlation Matrix nonparametric Spearman $(\rho)$ and the probability $(p)$ between the spatially weighted indices (Herfindahl $\left(H_{s}\right)$, Concentration -Press $\left(G_{s}\right)$ and Ellison-Glaeser $\left(\gamma_{s}\right)$ for the year 2010

\begin{tabular}{cccc}
\hline & $H_{s}$ & $G_{s}$ & $\gamma_{s}$ \\
\hline$H_{s}$ & $\mathbf{1 . 0 0 0 0}$ & & \\
$\mathrm{p}$ & & & \\
$G_{s}$ & $\mathbf{0 . 6 8 3 1}$ & $\mathbf{1 . 0 0 0 0}$ & \\
$\mathrm{p}$ & 0.0003 & & \\
$\gamma_{s}$ & $\mathbf{0 . 6 6 8 3}$ & $\mathbf{0 . 9 9 6 0}$ & $\mathbf{1 . 0 0 0 0}$ \\
$\mathrm{p}$ & 0.0005 & 0.0000 & \\
\hline
\end{tabular}

Source: Prepared by using Stata 12.0.

In general, it can be seen through this descriptive statistical analysis of spatially weighted indices for the year 2010 that the results were very satisfactory and consistent with all analysis throughout the article (especially the results of section 4.2). An analysis of the equations of this study was also of utmost importance for the explanation and participation of spatially weighted indices in the explanation of each value in a specific way, namely the indices: Herfindahl $\left(\mathrm{H}_{s}\right)$, Concentration-Press $\left(G_{s}\right)$ and Ellison and Glaeser $\left(\gamma_{s}\right)$.

The importance of considering spatial changes in the models and methods of analysis, in general, was highlighted by Luc Anselin, in 1988 when he published the book "Spatial Econometrics: Methods and Models", which unified several concepts and terminologies into a single unit. This eighties, the U.S. was a major center 
for the development of spatial econometrics, with scholars like himself Anselin, Keilejian, Prucha and Cressie (ANSELIN, 1988). The first spatial effect refers to the spatial dependence given by the interaction of agents in space. This entire process is subject to the so-called Law Tobler, whose essence can be understood as: "everything depends on everything else, but that is closest depends more". Thus, the Act Tobler emphasizes the role of proximity to the establishment of spatial interaction between the phenomena. For Almeida (2004, p. 9-10), spatial data determining the variation of a particular phenomenon considering such variation in the space. Therefore, the data have a spatial component referring to the phenomenon under study and other spatial nature, providing the reference in terms of the geographical location of this attribute.

Thus, the evolution of how the definition and scope of spatial econometrics are expressed over time and reflects a major shift in the field from the margins applied in urban and regional economic analysis into the mainstream of economics and other social sciences. Due to these fundamental questions discussed so far, this research became distinguished as an important discussion, innovating in the quantification of economic concentration space considering the presence of neighbors in the process of concentration of industrial activities in Brazil.

\section{References}

ALMEIDA, E. S. Curso de econometria espacial aplicada. Piracicaba: Universidade de São Paulo: Escola Superior de Agricultura Luiz de Queiroz. 2004.

ANSELIN, L. Spatial econometrics: methods and models. Boston: Kluwer Academic, 1988.

ARBIA, G. The role of spatial effects on the empirical analysis of regional concentration. Journal of Geographical Systems, v. 3, n. 3, p. 271-281. Nov. 2001.

BIDERMAN, C. Concentração das atividades produtivas no Brasil: diferenças inter-setoriais, regionais e sua dinâmica. São Paulo: Fundação Getúlio Vargas, Instituto de Pesquisas Econômicas, Programa de Seminários Acadêmicos, 2004. (Seminário n. 1/2004 - FGV-EESP).

BRASIL. Ministério do Trabalho e Emprego. Relação anual de informações sociais. Brasília, DF: MTE, 2010.

BUNCHAFT, G.; KELLNER, S. R. O. Estatística sem mistérios. 2. ed. Petrópolis: Vozes, 1999. v. 2.

CAMARGO, O. S. As mudanças na organização e localização da indústria automobilística brasileira (1996-2001). 2006. Tese (Doutorado em Economia) - Centro de Desenvolvimento e Planejamento Regional, Faculdade de Ciências Econômicas, Universidade Federal de Minas Gerais, Belo Horizonte, 2006.

CLIFF, A.; ORD, J. Spatial processes, models and applications. London: Pion, 1981. 
DURANTON, G.; OVERMAN, H. Exploring the detailed location patterns of UK manufacturing industries using Microgeographic Data. Journal of Regional Science, v. 48, n. 1. p. 213-243, Feb. 2008.

. Testing for localization using Micro-Geographic Data. Review of Economic Studies, v. 72, n. 4. p. 1077-1106, 2005.

ELLISON, G.; GLAESER E.; KERR, W. What causes industry agglomeration? Evidence from coagglomeration patterns. Washington, D.C. Center for Economic Studies, U. S. Census Bureau, Apr. 2007. (Discussion Papers, n. 7-13).

ELLISON, G.; GLAESER, E. Geographic concentration in U.S. manufacturing industries: a dartboard approach. Journal of Political Economy, v. 105, n. 5. p. 889-927, 1997.

GUILFORD, J. P. Fundamental statistics in psychology and education. 4. ed., New York: McGraw-hill Book, 1950.

GUIMARÃES, P.; FIGUEIREDO, O.; WOODWARD, D. Accounting for neighboring effects in measures of spatial concentration. Journal of Regional Science, v. 51, n. 4, p. 678-693, Apr. 2011.

. Measuring the localization of economic activity: a parametric approach. Journal of Regional Science, v. 47, n. 4, p. 753-774, Oct. 2007.

HERFINDAHL, O. C. Concentration in the US Steel Industry. Ph.D. dissertation. Columbia University, New York City, 1950.

HOOVER, E. Location theory and the shoe and leather industries. Cambridge: Harvard University Press. 1936.

IBGE. Economia. Indicadores. Indústria. Dados Secundários. Rio de Janeiro, RJ: IBGE, 2010.

KRUGMAN, P. R. Geography and trade. Cambridge: Leuvan University Press. Belgium/MIT Press, 1991.

KUPFER, D. Trajetórias de reestruturação da indústria brasileira após a abertura e a estabilização. 1998. 185 f. Tese (Doutorado em Economia), Instituto de Economia, Universidade Federal do Rio de Janeiro, Rio de Janeiro, 1998.

LAFOURCADE, M.; MION, G. Concentration, agglomeration and the size of plants. Regional Science and Urban Economics, v. 37, n. 1, p. 46-68, 2007.

LAUTERT, V.; ARAÚJO, N. C. M. Concentração industrial no Brasil no período 1996-2001: uma análise por meio do índice de Ellison e Glaeser (1994). Economia Aplicada, Ribeirão Preto, v. 11, n. 3, p. 347-368, jul.-set. 2007.

MARCON, E.; PUECH, F. Evaluating the geographic concentration of industries using distancebased methods. Journal of Economic Geography. v. 3, n. 4, p. 409-428, 2003.

MAUREL, F.; SEDILLOT, B. A measure of the geographic concentration in French manufacturing industries. Regional Science and Urban Economics, v. 29, n. 5, p. 575-604, 1999. 
MILONE G. Estatística geral e aplicada. São Paulo: Pioneira Thomson Learning, 2004.

NAJBERG, S.; OLIVEIRA, P. A. S. A dinâmica recente do emprego formal no Brasil. Rio de Janeiro: BNDES, 1999.

RESENDE, M.; WYLLIE, R. Aglomeração industrial no Brasil: um estudo empírico. Estudos Econômicos, São Paulo, v. 35, n. 3, p. 433-460, jul.-set 2005.

SIEGEL, S. Estatística não-paramétrica: para as ciências do comportamento. São Paulo: McGraw-Hill do Brasil, 1975.

SOUZA, F. L. A localização da indústria de transformação brasileira nas últimas três décadas. 2002. 130 f. Dissertação (Mestrado em Economia) - Escola de Pós-graduação em Economia, Fundação Getúlio Vargas, Rio de Janeiro, 2002.

WEBER, A. Theory of the location of industries. Chicago: The University of Chicago Press, 1929.

Recebido em: 06/01/14. Aceito em: 11/09/14. 